\title{
Article \\ Co-Developing an Antibiotic Stewardship Tool for Dentistry: Shared Decision-Making for Adults with Toothache or Infection
}

\author{
Wendy Thompson ${ }^{1,2, *}\left(\mathbb{D}\right.$, Jonathan Sandoe ${ }^{3}\left(\mathbb{D}\right.$, Sue Pavitt ${ }^{2}$, Tanya Walsh ${ }^{1}\left(\mathbb{C}\right.$ and Lucie Byrne-Davis ${ }^{4}(\mathbb{C}$ \\ 1 Division of Dentistry, University of Manchester, Manchester M13 9PL, UK; tanya.walsh@manchester.ac.uk \\ 2 School of Dentistry, University of Leeds, Leeds LS2 9JT, UK; S.pavitt@leeds.ac.uk \\ 3 School of Medicine, University of Leeds, Leeds LS1 3EX, UK; j.sandoe@leeds.ac.uk \\ 4 Division of Medical Education, University of Manchester, Manchester M13 9PL, UK; \\ lucie.byrne-davis@manchester.ac.uk \\ * Correspondence: wendy.thompson15@nhs.net; Tel.: +44-7837-190-387
}

Citation: Thompson, W.; Sandoe, J.; Pavitt, S.; Walsh, T.; Byrne-Davis, L. Co-Developing an Antibiotic Stewardship Tool for Dentistry: Shared Decision-Making for Adults with Toothache or Infection.

Antibiotics 2021, 10, 1345. https://

doi.org/10.3390/antibiotics10111345

Academic Editor: David Gillespie

Received: 17 October 2021

Accepted: 2 November 2021

Published: 4 November 2021

Publisher's Note: MDPI stays neutral with regard to jurisdictional claims in published maps and institutional affiliations.

Copyright: (c) 2021 by the authors. Licensee MDPI, Basel, Switzerland. This article is an open access article distributed under the terms and conditions of the Creative Commons Attribution (CC BY) license (https:// creativecommons.org/licenses/by/ $4.0 /)$.

\begin{abstract}
Dentistry is responsible for around 10\% of antibiotic prescribing across global healthcare, with up to $80 \%$ representing inappropriate use. Facilitating shared decision-making has been shown to optimise antibiotic prescribing (antibiotic stewardship) in primary medical care. Our aim was to co-develop a shared decision-making antibiotic stewardship tool for dentistry. Dentists, patients and other stakeholders prioritised factors to include in the new tool, based on previous research (a systematic review and ethnographic study) about dentists' decision-making during urgent appointments. Candidate behaviour-change techniques were identified using the Behaviour Change Wheel and selected based on suitability for a shared decision-making approach. A 'think aloud' study helped fine-tune the tool design and Crystal Marking ensured clarity of messaging. The resulting paper-based worksheet for use at point-of-care incorporated various behaviour change techniques, such as: 'information about (and salience of) health consequences', 'prompts and cues', 'restructuring the physical (and social) environment' and 'credible sources'. The think aloud study confirmed the tool's acceptability to dentists and patients, and resulted in the title: 'Step-by-step guide to fixing your toothache.' Further testing will be necessary to evaluate its efficacy at safely reducing dental antibiotic prescribing during urgent dental appointments in England and, with translation, to other dental contexts globally.
\end{abstract}

Keywords: antibiotic; stewardship; decision making; shared; dental; toothache; infection; primary healthcare; behavioural influences; dental procedures

\section{Introduction}

Antimicrobial resistance is a significant threat to global health, wealth and well-being, and is driven by the use of antibiotics [1]. The World Health Organisation global action plan on tackling antimicrobial resistance, therefore, seeks to optimise the use of antimicrobials in human and animal health (known as antimicrobial stewardship) [1]. The United Kingdom (UK) Government 20-year vision is for strong antimicrobial stewardship and diagnostic stewardship, by ensuring all decisions are supported by diagnostic tests and decision-support tools [2]. Dentistry accounts for around 10\% of antibiotic (antibacterial drug) prescribing across international healthcare, with up to $80 \%$ shown to represent overprescribing [3]. In England's publicly funded National Health Service (NHS), urgent dental care for people with acute dental pain or infection accounts for most dental antibiotics, with around 90\% of them for adults [4]. In 2020, 3.0 million antibiotics were dispensed to dental patients, costing NHS England £7.6M [5].

Unlike in medical settings, where many common infections are amenable to selfcare [6], acute dental pain and infection will usually recur without a procedure [7]. As dental infections have the potential to spread rapidly to become life-threatening conditions, all dental surgeons are skilled to diagnose and manage dental pain and infection using 
dental procedures (such as extraction of a tooth) usually without the need for antibiotics [3]. In addition, all dental practices in the UK are equipped to diagnose bacterial infections during consultations, for example with radiographs [8]. Safely reducing dental antibiotic prescribing for people with people with acute dental pain or infection must, therefore, be associated with an increase in the number of dental procedures.

Compared to medicine, few antibiotic stewardship interventions have been developed to optimise dental antibiotic prescribing [9]. Facilitating shared decision has proved a successful way to reduce antibiotic prescribing in primary medical care [10], but is untested in dentistry. To inform the development of new antibiotic stewardship approaches for primary dental care, several studies have identified potentially modifiable factors which influence the decision whether to prescribe antibiotics which could be suitable for inclusion in a behaviour change intervention $[9,11]$. Whilst many of the thirty-one factors identified were common across both medical and dental settings, some were previously unreported in any primary healthcare setting. Examples included: the clinician's goal to fix the problem during the urgent appointment (so as to prevent it recurring) rather than just providing symptomatic (e.g., pain) relief, and clinicians' beliefs about whether providing a procedure (such as draining an infection) was possible during an urgent appointment.

In 2016, a dental antimicrobial stewardship toolkit was introduced in England to provide free, online access to guidelines, information and training about dental antibiotic prescribing and resistance [12]. Large gaps in the toolkit have been identified, however, between the thirty-one factors influencing antibiotic prescribing by dentists and the relatively few factors (mainly clinician knowledge) addressed in the toolkit (through clinician guidelines, education and self-audit) [13]. Significant potential exists, therefore, to design a new dental antibiotic stewardship tool to complement those within the existing toolkit, especially in relation to clinician beliefs, professional identity and influence by other people.

The purpose of this paper is to report the development of an evidence-based, behaviour theory-informed, shared decision-making tool to optimise antibiotic prescribing by dentists, for adults with acute dental pain or infection, during urgent dental appointments, initially in England. In line with the ethos of shared decision-making (where equal partnerships and patient empowerment are key), a co-development approach with dentist, patients and other stakeholders was chosen. If shown to be successful at reducing dental antibiotic prescribing, this tool will be translated into other dental contexts worldwide to contribute towards global efforts to tackle antimicrobial resistance.

\section{Results}

\subsection{Stage 1-Understanding the Behaviour/Prioritising Factors}

Dentists, patients and the other stakeholders reached a consensus on prioritisation of nine factors (from thirty-one factors identified in a published ethnographic study [11]) for inclusion in this new dental antibiotic stewardship tool: 'antibiotic beliefs', 'competing demands', 'fix the problem', 'patient influence', 'patient management', 'peers and colleagues', 'planning and consent', 'procedure possible' and 'professional role'. Of these, seven had also been identified previously in a systematic review of factors associated with dentists' decision whether to prescribe antibiotics for adults with acute dental conditions [9].

To underpin intervention development, the first stakeholder meeting began the process of prioritising the factors associated with the decision whether to prescribe dental antibiotics. Having also reviewed antibiotic stewardship interventions developed for use in the primary medical care context, the stakeholders recommended translation of two key aspects for the new dental antibiotic stewardship tool:

(1) Engaging patient in (rather than just giving them a leaflet or telling them the treatment decision) during urgent dental appointments; and

(2) The use of diagrams on a leaflet (as per the Royal College of General Practitioner's Urinary Tract Infection self-management leaflet of the Treat Antibiotics Responsibly: Guidance, Education Tools (TARGET) toolkit) to nudge and assist the dentist to explain the diagnosis to the patient [14]. 


\subsection{Stage 2-Identification of Behaviour Change Techniques}

Based on the mapping of each factor to domains of the Theoretical Domains Framework (TDF) (as per the original publication [11]) and using the Theory and Techniques Tool (TTT) [15], candidate behaviour change techniques (BCTs) were identified. BCTs that were assessed to fit with a shared decision-making approach are presented in Table 1. Identification and assessment of the candidate BCTs are presented in detail within Supplementary Materials Table S1.

Table 1. Factors that affect decision-making by dentists during urgent dental appointments prioritised for intervention development, mapped to the Theoretical Domains Framework (TDF) and with the selected Behaviour Change Techniques (BCTs).

\begin{tabular}{|c|c|c|}
\hline Priority Factors & TDF & BCT \\
\hline Antibiotic beliefs & $\begin{array}{l}\text { Beliefs about } \\
\text { consequences }\end{array}$ & $\begin{array}{l}\text { Information about health } \\
\text { consequences } \\
\text { Salience of health consequences }\end{array}$ \\
\hline Competing demands & $\begin{array}{c}\text { Environmental } \\
\text { context and resources }\end{array}$ & $\begin{array}{l}\text { Prompts and cues } \\
\text { Restructuring the social environment } \\
\text { Adding objects to the environment }\end{array}$ \\
\hline Fix the problem & Goals & Goal setting (behaviour) \\
\hline Patient influence & Social influences & $\begin{array}{l}\text { Restructuring the social } \\
\text { environment }\end{array}$ \\
\hline Patient management & Skills & $\begin{array}{l}\text { Instructions on how to } \\
\text { perform the behaviour }\end{array}$ \\
\hline Peers and colleagues & Social influences & $\begin{array}{l}\text { Restructuring the social environment } \\
\text { Structuring the physical environment }\end{array}$ \\
\hline Planning and consent & $\begin{array}{l}\text { Beliefs about } \\
\text { capabilities }\end{array}$ & $\begin{array}{l}\text { Verbal persuasion } \\
\text { about capability }\end{array}$ \\
\hline Procedure possible & $\begin{array}{l}\text { Beliefs about } \\
\text { capabilities }\end{array}$ & $\begin{array}{l}\text { Verbal persuasion } \\
\text { about capability }\end{array}$ \\
\hline Professional role & $\begin{array}{l}\text { Professional } \\
\text { role and identity }\end{array}$ & Credible source \\
\hline
\end{tabular}

A worksheet format for the tool was chosen to engage the patient in the decisionmaking process and included diagrams to explain the diagnosis (as advised by the stakeholders in Stage 1). A draft worksheet (see Supplementary Materials Figure S1) was developed, incorporating the identified factors and BCTs, (see Table 1) including information about salient health consequences of unnecessary antibiotic prescribing. The draft worksheet was structured to prompt elicitation of patient preferences and values (an essential component of shared decision-making [16]). The presence of the worksheet in urgent dental clinics would add an object to the environment to help deal with competing demands, and at the same time, act to restructure the social environment relating to both patients and colleagues across the whole dental team. Recognisable logos within the worksheet would provide a credible source to support the dental professionals accepting the tool as relevant to their role and identity.

\subsection{Stage 3-Planning to Deliver the Tool and Acceptability Testing}

During the think aloud study, the stakeholders provide advice about the content and structure of the worksheet which informed modification of the draft worksheet (see Table 2). 
Table 2. Details of feedback from the stakeholders and resulting modifications made to the draft worksheet.

\begin{tabular}{|c|c|c|}
\hline $\begin{array}{l}\text { Worksheet } \\
\text { Section/Issue }\end{array}$ & Feedback from Stakeholders & Resulting Modification \\
\hline $\begin{array}{l}\text { Title and 'What is this } \\
\text { leaflet for? section }\end{array}$ & $\begin{array}{l}\text { Suggested title: 'Step-by-step } \\
\text { guide to fixing your toothache'. } \\
\text { Add the dentist's name. }\end{array}$ & $\begin{array}{l}\text { Title changed accordingly and a } \\
\text { space for the dentist's name (to } \\
\text { be written by the clinic's } \\
\text { reception team) was added. }\end{array}$ \\
\hline 'Notes' section & $\begin{array}{l}\text { More structure required and } \\
\text { located earlier in the worksheet. } \\
\text { 'Provide more structure to this } \\
\text { section to get me to think about my } \\
\text { problem. And then ask me if I think } \\
\text { I might need antibiotics!' (Patient } \\
\text { participant) } \\
\text { A dentist participant suggested } \\
\text { asking patients about their } \\
\text { anxiety which can be a problem } \\
\text { in urgent dental appointments. }\end{array}$ & $\begin{array}{l}\text { New section added: 'Before your } \\
\text { appointment' and included } \\
\text { visual analogue scales for pain } \\
\text { and anxiety, plus free text for } \\
\text { patient's expectations. }\end{array}$ \\
\hline $\begin{array}{l}\text { 'Do I need antibiotics?' } \\
\text { section }\end{array}$ & $\begin{array}{l}\text { Essential section. Advised } \\
\text { locating where it could be read } \\
\text { by patients whilst waiting to see } \\
\text { the dentist without being the } \\
\text { primary focus of the worksheet. }\end{array}$ & $\begin{array}{l}\text { Relocated after the 'Before your } \\
\text { appointment' section. }\end{array}$ \\
\hline $\begin{array}{l}\text { 'What is causing my } \\
\text { dental problem?' section }\end{array}$ & $\begin{array}{l}\text { Diagrams essential to help } \\
\text { explain the cause of symptoms to } \\
\text { patients, but could be clearer: } \\
\text { '... don't need to be a double tooth. } \\
\text { Just include a healthy one at the top.' } \\
\text { (Patient participant) }\end{array}$ & $\begin{array}{l}\text { The diagrams were simplified in } \\
\text { line with the advice. }\end{array}$ \\
\hline Issue of credibility & $\begin{array}{l}\text { Credible source essential. } \\
\text { A dentist participant noted 'It } \\
\text { needs to look official. Good quality } \\
\text { paper. And can you add the NHS } \\
\text { logo?' }\end{array}$ & $\begin{array}{l}\text { Permission was obtained to use } \\
\text { the recognisable 'Antibiotics } \\
\text { Don't Cure Toothache' logo from } \\
\text { the UK dental antimicrobial } \\
\text { stewardship toolkit, and the } \\
\text { Crystal Mark added credibility } \\
\text { to the worksheet. }\end{array}$ \\
\hline Issue of format & $\begin{array}{l}\text { Concerns about a digital version } \\
\text { included digital exclusion. } \\
\text { Concerns about a paper-based } \\
\text { version included colour printing, } \\
\text { as some dental practices only } \\
\text { have black and white printers. }\end{array}$ & $\begin{array}{l}\text { A paper-based format with } \\
\text { colours which are clear when } \\
\text { printed in either colour or black } \\
\text { and white. }\end{array}$ \\
\hline Issue of dentist's ability & $\begin{array}{l}\text { Training need identified: ' ... } \\
\text { training to teach dentists how to } \\
\text { explain things like antibiotic-related } \\
\text { colitis.' (Dentist participant) }\end{array}$ & $\begin{array}{l}\text { During implementation, the } \\
\text { on-line training package to } \\
\text { accompany the worksheet would } \\
\text { cover this skill. }\end{array}$ \\
\hline
\end{tabular}

The think aloud study also demonstrated to the researchers that the folded design (to reveal the panels to the patient in a specific order) was too complex. Printing out the leaflet and folding it in the right way was, therefore, a barrier to its use in the intended way. This informed redesign of the worksheet to a more flexible two sides of A4 which could be printed back-to-back and folded if desired. Following feedback from the dentists and dental nurses, colours for the leaflet were also chosen which appeared equally well when printed in black and white as colour, as not all dental practices have colour printers. 


\subsubsection{Description of the Worksheet}

The worksheet to facilitate shared decision-making consisted of six sections printed 'back to back' on a single sheet of paper. Side one consisted of three sections (see Figure 1) and was designed for use by the patient whilst waiting to meet the dentist for their urgent dental care. Side 2 also contained three sections (see Figure 2) and was designed for the dentist to complete with the patient during the appointment, and for the patient to take home afterwards.
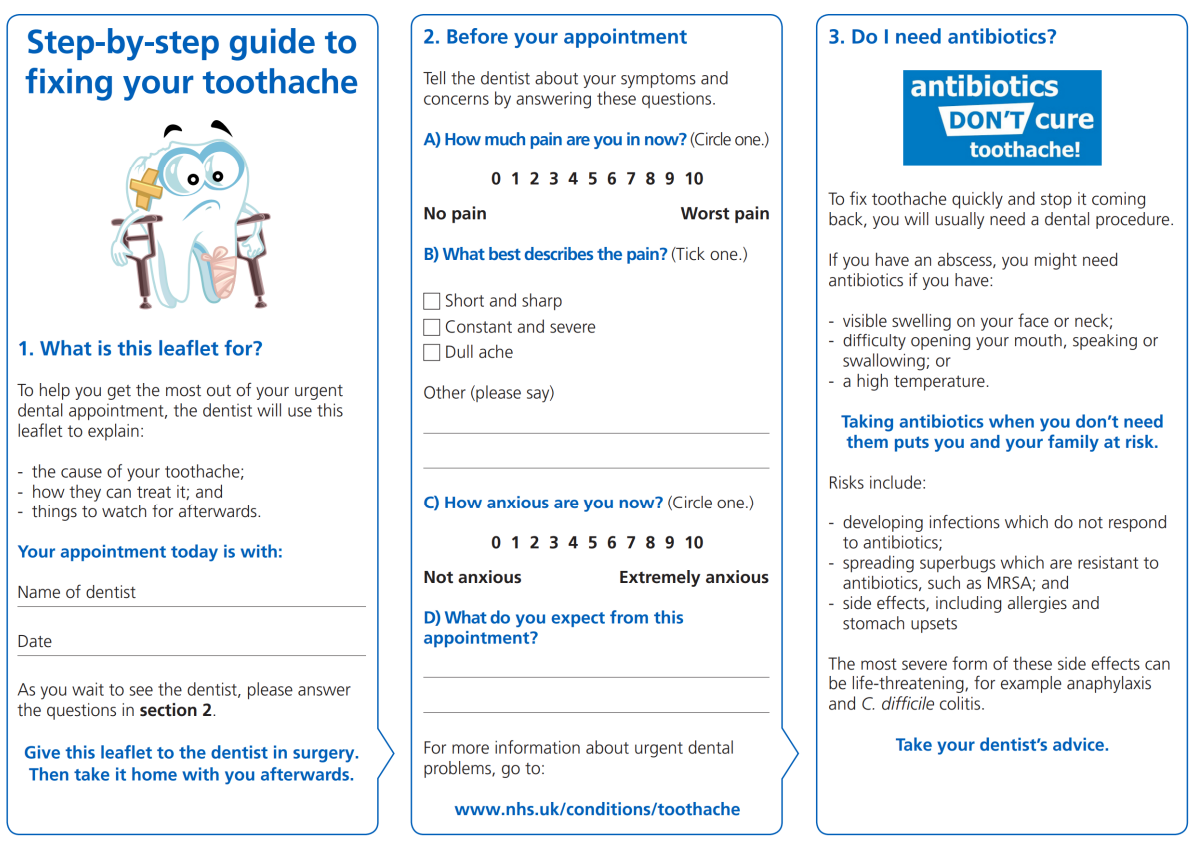

Figure 1. Side one of the shared decision-making worksheet, coproduced to optimise dental antibiotic prescribing during urgent dental appointments. Reproduced with permission of University of Leeds.
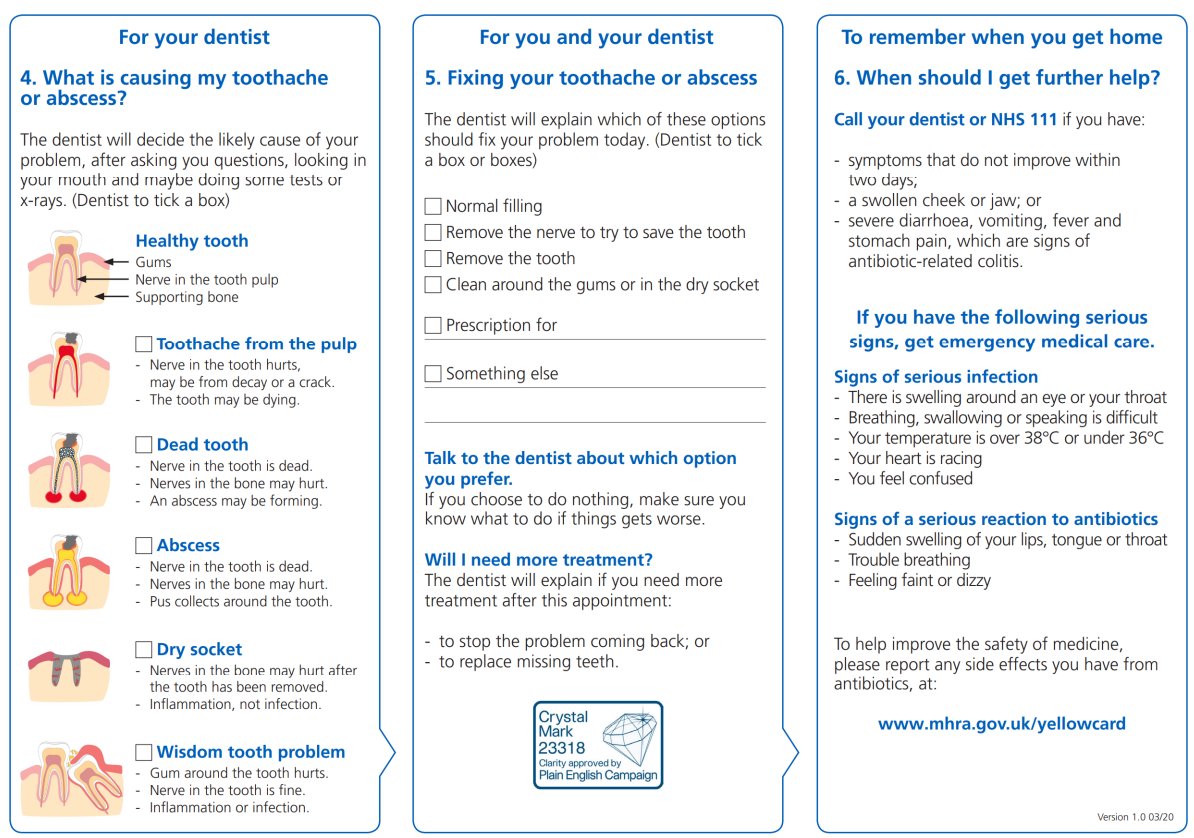

Figure 2. Side two of the shared decision-making worksheet coproduced to optimise dental antibiotic prescribing during urgent dental appointments. Reproduced with permission of University of Leeds. 
Each section of the worksheet was linked to the priority BCTs, as detailed in Table 3 and, additionally, Section 4 contributed to delivery of the UK Government's 20-year vision for tackling antimicrobial resistance through diagnostic stewardship by nudging dentists to make a diagnosis.

Table 3. Details of the content and behaviour change techniques (BCTs) within each section of the shared decision-making, dental antibiotic stewardship tool.

\begin{tabular}{|c|c|c|}
\hline Section & Content & BCT \\
\hline $\begin{array}{l}\text { 1. What is this } \\
\text { leaflet for? }\end{array}$ & $\begin{array}{c}\text { Reception completes Section } 1 \text { and } \\
\text { hands the worksheet to the patient, } \\
\text { thus engaging them in optimising } \\
\text { urgent dental care. }\end{array}$ & $\begin{array}{l}\text { Restructuring the social } \\
\text { environment } \\
\text { Adding objects to the } \\
\text { environment }\end{array}$ \\
\hline $\begin{array}{l}\text { 2. Before your } \\
\text { appointment }\end{array}$ & $\begin{array}{l}\text { Patient completes their pain, anxiety } \\
\text { and other information, and hands the } \\
\text { worksheet to the dentist, thus } \\
\text { prompting the dentist to dedicate } \\
\text { time to understanding the patient } \\
\text { perspective. }\end{array}$ & Prompts and cues \\
\hline $\begin{array}{l}\text { 3. Do I need } \\
\text { antibiotics? }\end{array}$ & $\begin{array}{l}\text { Provides information about the risks } \\
\text { of antibiotics. } \\
\text { 'Antibiotics Don't Cure Toothache' } \\
\text { branding adds credibility }\end{array}$ & $\begin{array}{c}\text { Information about health } \\
\text { consequences } \\
\text { Salience of health } \\
\text { consequences } \\
\text { Credible source }\end{array}$ \\
\hline $\begin{array}{l}\text { 4. What is causing my } \\
\text { toothache or } \\
\text { abscess? }\end{array}$ & $\begin{array}{l}\text { Environment restructured so the } \\
\text { patient expects to be told a diagnosis. } \\
\text { Diagrams nudging and assisting the } \\
\text { dentist to explain the diagnosis. }\end{array}$ & $\begin{array}{c}\text { Restructuring the social } \\
\text { environment } \\
\text { Prompts and cues }\end{array}$ \\
\hline $\begin{array}{l}\text { 5. Fixing your } \\
\text { toothache or } \\
\text { abscess }\end{array}$ & $\begin{array}{l}\text { Prompts the dentist to explain } \\
\text { treatment options and share } \\
\text { decision-making. } \\
\text { Empowers the patient. } \\
\text { The Crystal Mark adds credibility to } \\
\text { the workbook. }\end{array}$ & $\begin{array}{l}\text { Prompts and cues } \\
\text { Credible source }\end{array}$ \\
\hline $\begin{array}{l}\text { 6. When should I get } \\
\text { further help? }\end{array}$ & $\begin{array}{l}\text { Provides safety netting advice } \\
\text { (Information about what to do if the } \\
\text { treatment provided fails). } \\
\text { Referencing the Medicines and } \\
\text { Healthcare products Regulatory } \\
\text { Agency adds credibility. }\end{array}$ & $\begin{array}{l}\text { Information about health } \\
\text { consequences } \\
\text { Credible source }\end{array}$ \\
\hline
\end{tabular}

\subsubsection{Planning to Deliver the Worksheet Tool as Part of a Wider Intervention}

Several of the BCTs prioritised by the stakeholders for intervention development were not encompassed within the worksheet: instruction on how to perform the behaviour, verbal persuasion about capability and goal setting (behaviour). As highlighted by one of the dentist participants in the think aloud study (Section 2.3), the dentists using this tool would require training, for example to learn how to explain the risks of antibiotic use, such as 'antibiotic-related colitis'.

An online, motivational training package for dentists to accompany use of the tool is being developed, therefore, as part of the shared decision-making, dental antibiotic stewardship intervention. As well as introducing the dentists to using the worksheet, it will address instruction and persuasion relating to dentists' skills in 'patient management' (including the processes of diagnosis, treatment planning and consent) and their beliefs about their capabilities for diagnosing, treatment planning, gaining consent and providing dental procedures during urgent appointments. It will also set the goal of urgent dental appointments to be about 'fixing the acute dental problem' with definitive treatment wherever possible (in line with the NHS commissioning standard for urgent dental care [17]), rather than just aiming to provide symptomatic relief of pain or infection. This online training is 
being developed in collaboration with Health Education England (the UK Government's public body which provides education and training to the health workforce) and will be delivered by a source seen a credible by NHS dentists providing urgent dental care in England, such as an academic institution or professional body.

\subsection{Logic Model for the Shared Decision-Making, Dental Antibiotic Stewardship Intervention}

A logic model for the shared decision-making, dental antibiotic stewardship intervention (incorporate the worksheet, together with an accompanying online, motivational training package) is presented in Figure 3. The logic model demonstrates how the inputs, activities and participants are intended to deliver impact.
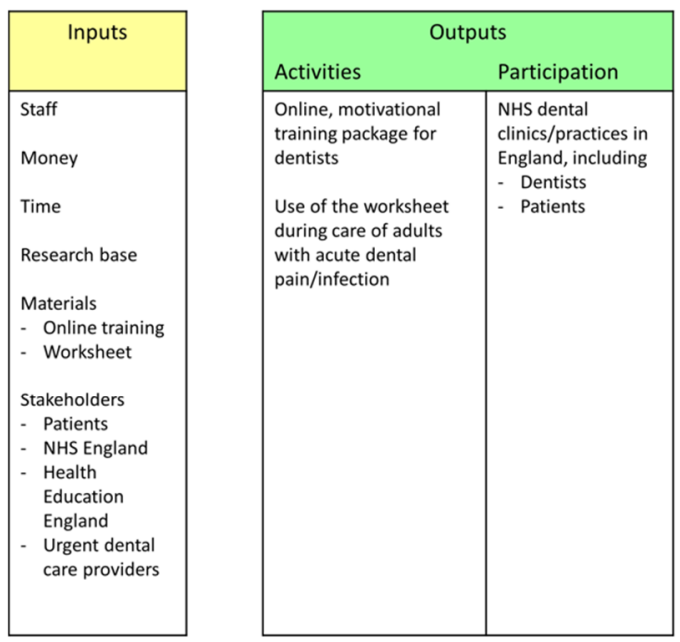

Assumptions

Dental teams and patients will engage with the intervention.

\begin{tabular}{|c|c|c|}
\hline \multicolumn{3}{|c|}{ Outcomes = Impact } \\
\hline Short & Medium & Long-term \\
\hline $\begin{array}{l}\text { Beliefs } \\
-\uparrow \text { belief about } \\
\text { risks of antibiotic } \\
\text { resistance } \\
-\uparrow \text { belief that } \\
\text { procedures } \\
\text { possible during } \\
\text { urgent dental visits } \\
\text { Skills } \\
-\uparrow \text { patient } \\
\text { management skills } \\
\text { Environment } \\
-\quad \text { patient } \\
\text { influence for } \\
\text { antibiotics } \\
-\quad \text { support of } \\
\text { wider dental team } \\
\text { for guideline } \\
\text { congruent care }\end{array}$ & $\begin{array}{l}\text { Cost savings to } \\
\text { NHS from } \downarrow \text { drug } \\
\text { prescribing. } \\
\\
\uparrow \text { guideline } \\
\text { congruent care. } \\
\\
\text { Improved } \\
\text { outcomes of } \\
\text { urgent dental care } \\
\text { ( } \uparrow \text { fixed } \\
\text { pain/infection and } \\
\text { satisfied patients; } \\
\downarrow \text { complications) }\end{array}$ & $\begin{array}{l}\text { Dentists contribute } \\
\text { to WHO Global } \\
\text { action plan on } \\
\text { antimicrobial } \\
\text { resistance via: } \\
\text { UK 20-yr Vision for } \\
\text { strong AMS by } \\
\text { ensuring all } \\
\text { decisions are } \\
\text { supported by } \\
\text { diagnostic tests } \\
\text { and decision } \\
\text { support. } \\
\text { Cost savings to } \\
\text { NHS from } \downarrow \\
\text { adverse outcomes } \\
\text { e.g. AMR, C. } \\
\text { difficile etc }\end{array}$ \\
\hline
\end{tabular}

External Factors

Pandemic impact on urgent dental services

Figure 3. Logic model for the shared decision-making, dental antibiotic stewardship intervention (including the worksheet tool and accompanying online, motivational training package).

\section{Discussion}

A shared decision-making tool, which is tailored to urgent NHS dentistry in England and acceptable to patients and dentists in this context, has been developed to optimise antibiotic prescribing by dentists for adults with acute dental pain or infection. A stakeholder group of patients and members of the dental team co-produced the worksheet and focused content on the behavioural influences which they judged as the highest priority to be tackled. Further work to develop an accompanying online motivational training package is underway. Evaluation of the intervention (both worksheet and training) during urgent dental appointments will follow.

Using an evidence-based system for intervention development was an important strength of this study. The behaviour change wheel $(\mathrm{BCW})$ provided the theoretical framework $[18,19]$, with the Theory \& Techniques Tool (TTT) proving a useful instrument to support co-development of the worksheet, and streamlining the conventional BCW process by providing a direct link between BCTs and TDF domains [20]. In doing so, it removed the step to 'identify intervention functions or policy categories' [18] and enabled focus on just the BCTs which were potentially capable of delivering the desired behaviour change [15].

For development of this shared decision-making intervention (which is about levelling the playing field between patients and clinicians), the researchers viewed sharing responsibility and power between stakeholders and researchers as essential to the ethos of the project. Whilst patient and public involvement and engagement in research are now an expected component of research activity in the UK [21], the researchers wanted to go beyond this requirement, by including stakeholders in all aspects of this project. Stake- 
holders were first involved as members of the steering group which shaped and oversaw delivery of the research programme from its earliest stages. This included supporting a systematic review study [9] which was undertaken whilst also applying for initial funding of the ethnographic study to understand the factors influencing the decision whether to prescribe antibiotics [11]. Involvement continued and expanded through the stakeholder groups to prioritise the factors for intervention development and participation in the think aloud study reported in this paper. Stakeholder involvement has evolved over time and, whilst some of the original stakeholders have now ceased involvement, new stakeholders have joined as we work towards full-scale evaluation of this intervention.

Co-production has been defined as 'collaboration in governance, priority-setting, conducting research and/or knowledge translation' [22]. Tension among the co-production team is a recognised challenge of co-production [20,23]. Attention to power imbalances, difficult discussions about research rigour versus research relevance, and constant monitoring are advocated to help mitigate this risk $[24,25]$. Through an established relationships with the lead expert by experience (who sat also on the project's external steering group), use of facilitators experienced in community engagement and development to lead the two workshop sessions, and keeping the project tightly focused on its ambition (and therefore timescales), these challenges were managed and avoided during this study.

Think aloud studies provide a constructive way to show the acceptability of an intervention and have been hypothesised to improve the uptake and adherence thus leading to a greater change in behaviour when implemented in healthcare [26]. Using a think aloud approach is a further strength for this study as it provided feedback from end users (who live and work across England from the southwest to northeast) which enabled fine tuning of the worksheet's content and presentation for relevance across the NHS England regions.

High rates of antibiotic overprescribing (not in accordance with guidelines) are known to exist across NHS medical and dental care [26-28]. Promulgating clinical practice guidelines is known to have limited effect on changing clinician behaviour [29] and bundles of interventions to optimise antibiotic prescribing across healthcare have been shown to be beneficial [30]. Interventions that facilitate shared decision-making between patients and clinicians are included in bundles for use in primary medical care [31], but no such tools have been reported in primary dental care [32]. While our shared decision-making tool is designed to change the prescribing behaviour of dentists, it is recognised that it will also act on the behaviour of patients [33] and other dental team members (e.g., receptionists [34]). By reducing the expectation that antibiotics will be prescribed, the intervention will also address the 'peers and colleagues' factor which is reported to influence dentists' decision whether to prescribe antibiotics [11].

In addition to the 31 dentist-factors associated with decision-making during urgent dental appointments, the ethnographic study feeding into this study also identified 19 patient-factors [11]. The strength of some patient's desire for antibiotics and their beliefs about the appropriateness of antibiotics for acute dental pain were highlighted [11]. The extent to which patients avoid seeking dental care for dental problems ( $72 \%$ did not consult a dentist) has recently been shown in a study of health-seeking behaviour across healthcare in England [35]. The widespread but mistaken belief that antibiotics are necessary for treating toothache, and an appropriate way to avoid dental treatment, has been demonstrated in a view of social media posts of Twitter and Facebook [33].

Some patients in the ethnographic study exhibited well-developed negotiation/ communication skills [11], and bargaining for antibiotics has also been identified in studies undertaken in medical contexts [36,37]. Empowering patients by supporting communication between patient and clinicians has been identified in NHS primary medical care as another potentially important way of reducing overprescribing of antibiotics [38]. By facilitating shared decision-making, it is anticipated that the worksheet developed will also help improve dentist-patient communication, which has been identified as a priority for oral and dental research in England [39]. 
Other patients in the ethnographic study reported strongly emotional feelings about dental treatment (such as anxiety or phobia) [11]. Studies of dental anxiety have shown that providing the dentist with information of a patient's heightened anxiety prior to treatment, and involving the patient in this, reduced the patient's dental anxiety [40]. Anxiety was also identified in the social media review (of antibiotics and toothache) as a driver of antibioticseeking behaviour by dental patients [33]. For this reason, the worksheet includes an anxiety scale to facilitate that shared understanding about the patient's level of anxiety.

Antibiotics do not work for dental pain which is caused by an inflammatory process (such as pulpitis) [41]. Treatment of non-vital, abscessed teeth with antibiotics can only provide temporary relief (at best) and symptoms inevitably recur [42]. During the COVID19 pandemic, access to dental procedures was restricted in many countries and remote management with advice, analgesics and antibiotics was encouraged [43-45]. A UK Parliament report highlighted the impact of this approach which resulted in suboptimal outcomes for patients during the pandemic: 'patients have been remotely prescribed with antibiotics for their dental problems but have returned with pain or further swelling as the cause of their dental problem has not been properly addressed' [7]. It is anticipated that our shared decision-making tool will reduce antibiotic prescribing by increasing the number of dental procedures provided, in accordance with guidance.

The ethnographic study which underpins this intervention development also suggested that it takes longer to deliver dental procedures than antibiotics during urgent dental appointments [11]. A scenario-based questionnaire study has also shown that appointments shorter than $20 \mathrm{~min}$ are a risk factor for inappropriate antibiotic prescribing (not in accordance with guidelines) [46]. Furthermore, the National Institute for Health and Care Excellence guideline on shared decision-making places emphasises on providing enough time for people to make the decision that's right for them [16]. Further research is required, therefore, to test whether shared decision-making and guideline congruent care can be effectively delivered during the 15-min urgent dental appointments commissioned by the NHS in England [17], or whether longer appointments are required.

A limitation of this study is that the shared decision-making, dental antibiotic stewardship intervention resulting from this study focused on just 9 of the 31 factors identified as influences on dentists' decisions whether to prescribe antibiotics. A number of the factors not addressed by this intervention link to the wider environment context for urgent NHS dental care provided in England. These healthcare system factors include the access to (availability of) routine and specialist NHS dental services required to complete definitive treatment started during urgent dental appointments (such as root canal or provision of a denture to replace missing teeth). The lack of routinely collected dental prescribing data also makes it impossible to hold NHS dental contractors accountable for their dental antibiotic prescribing rates or to financially incentivise optimal urgent dental care through the NHS dental contract [13]. The importance of these health service levels factors was highlighted during the COVID-19 pandemic, when restricted access to dental procedures for treating acute dental pain and infection resulted in a dramatic $25 \%$ increase in dental antibiotic prescribing in England [43] compared to reductions in antibiotic use across all other parts of the NHS [47]. For such a health services-wide approach to be delivered for NHS dentistry in England, a complexity of changes (both legislative and technological) would be required. Further research to develop health services approaches for NHS dentistry (such as Quality Premium payments similar to those introduced to primary medical care in 2015 [48]) should be undertaken in preparation for the introduction of systems and processes to facilitate the routine collection of high-quality dental prescribing data, such as via an electronic prescribing system.

If shown to have the desired impact, translation of this intervention into other healthcare contexts would be straightforward. With seven of the nine factors targeted by this intervention having been identified in an international systematic review of dentists' decisionmaking about whether to prescribe antibiotics to adults with acute dental pain or infection (and the other two not previous reported on in dental studies), it is likely that translation 
between dental contexts will be successful. Testing of the intervention in urgent dental care in NHS England and beyond will be needed to assess the efficacy of this tool as an antibiotic stewardship intervention which could contribute to global efforts to tackle antibiotic resistance.

\section{Materials and Methods}

Development of the tool followed the Behaviour Change Wheel (BCW) approach [18], in three stages: (1) Understanding the behaviour and prioritising focus for action; (2) planning to produce the intervention; and (3) planning to deliver the intervention and acceptability testing. BCW encompasses a coherent suite of theories, techniques and tools which combines the plethora of existing behaviour theories and models to facilitate development of behaviour change interventions [18,49]. It includes the Theoretical Domains Framework (TDF), and Theory \& Techniques Tool (TTT). TDF provides a comprehensive, theory-informed approach to identify determinants of behaviour and support behaviour change intervention design [50]. The TTT can be used to identify links between TDF domains and behaviour change techniques (BCTs) based on evidence from the literature, expert consensus or triangulation [20].

\subsection{Stage 1-Understanding the Behaviour/Prioritising Factors}

Understanding dentists' antibiotic prescribing behaviour was based on 31 factors which had been identified in a previous ethnographic study about influences on treatment decisions (including but not limited to antibiotic prescribing) during urgent NHS dental appointments in England [11]. A stakeholder group of experts by experience of urgent dental care (i.e., patients), general dental practitioners (GDPs), dental nurses, NHS service managers, and healthcare researchers took part in two workshops to understand and prioritise factors for inclusion in one or more interventions. In total, 19 stakeholders were involved, including 4 experts by experience, 4 GDPs, 2 dental nurses, 4 managers, and 5 researchers). At the first workshop, three groups of 5 or 6 stakeholders worked with flashcards to become acquainted with each of the 31 factors. The groups were also asked to identify elements of existing antimicrobial stewardship tools $[14,35,46,47,51]$ which they would like to see translated into the new intervention for dentistry. A scribe from www.liveillustration.co.uk made a graphic (cartoon) record of the meeting, which acted to both collate ideas and stimulate discussion among the whole group about the factors and initial feelings about relative importance of each factor. The second stakeholder workshop was organised by a theatre arts charity (www.theatreofdebate) and was designed to broaden and deepen understanding and insight among the group about the factors before then prioritising them as targets for intervention development. To achieve consensus among the group about the priorities, eight pairs of stakeholders ranked their top three priorities, which they then shared and discussed among the whole group. Finally, through discussion, the group decided on the factors which they identified as priorities to include in interventions.

\subsection{Stage 2-Identification of Behaviour Change Techniques}

Each factor had been mapped to the TDF in previous studies $[9,11]$. The TTT was used to identify candidate BCTs directly from the TDF domains. The suitability of each candidate BCT for inclusion in the final intervention was assessed using the Affordability, Practicability, Effectiveness, Acceptability, Side effects/Safety, Equality (APEASE) criteria, as per BCW guidance [18] (see Supplementary Materials Table S1).

A draft worksheet was developed incorporating these BCTs and with reference to frameworks for shared decision-making [16] and advice from the stakeholder groups). The results were summarised in a logic model for the tool to facilitate shared decision-making between patients and dentists in order, ultimately, to contribute to the UK's delivery of the WHO global action plan on antimicrobial resistance [1]. 


\subsection{Stage 3-Planning to Deliver the Tool and Acceptability Testing}

A draft worksheet was developed by the principal researcher (WT), incorporating the BCTs and other elements identified during the stakeholder workshops. A think aloud study with key stakeholders (patients, dentists and dental nurses) was undertaken through interviews to check the content, to review preferences for the mode of delivery (face-toface with individuals or at distance with people accessing the intervention digitally) [18] and to fine tune the presentation of the material. A copy of the participant information sheet for the think aloud study, including questions used to collect feedback during the interviews, is provided as Supplementary Materials Figure S2. Following incorporation of the results of the think aloud study into a revised draft of the worksheet, the new draft was sent for Crystal-Mark approval (by www.plainenglish.co.uk) to confirm the clarity of the worksheet.

Ethical approval for the study was gained from the University of Leeds Dental Research Ethics Committee (DREC ref: 101218/WT/267 dated 18 December 2018).

\section{Conclusions}

A shared decision-making tool, comprising a worksheet with multiple behaviour change techniques built into the text, image content, and mode of delivery, has been produced which aims to reduce antibiotic prescribing for adult patients with toothache or infection during urgent NHS dental appointments in England. The next step will be to evaluate it at point of care and to translate it into other dental contexts so that dentistry around the world can contribute to international efforts to tackle antibiotic resistance.

Supplementary Materials: The following are available online at https: / www.mdpi.com/article / 10.3390 / antibiotics10111345/s1. Table S1: Mapping of prioritised factors with potential behaviour change techniques. Figure S1: Original draft of the worksheet used in the think aloud study. Figure S2: Participant information sheet used in the think aloud study.

Author Contributions: Conceptualisation, W.T.; methodology, W.T., S.P.; investigation, W.T., J.S.; resources, W.T., S.P.; data curation, W.T., L.B.-D.; supervision, J.S., S.P.; writing-original draft preparation, W.T.; writing—review and editing, W.T., L.B.-D., T.W., J.S., S.P.; visualisation, W.T., T.W., L.B.-D.; project administration, W.T.; funding acquisition, W.T., S.P. All authors have read and agreed to the published version of the manuscript.

Funding: This research was funded by National Institute for Health Research, grant number DRF2016-09-148.

Institutional Review Board Statement: The think aloud study was conducted according to the guidelines of the Declaration of Helsinki, and approved by the University of Leeds Dental Research Ethics Committee (DREC ref: 101218/WT/267 dated 18 December 2018).

Informed Consent Statement: Informed consent was obtained from all subjects involved in the think aloud study.

Acknowledgments: With thanks to all of the stakeholders who helped co-produce this research. Thanks also to Theatre of Debate for facilitating the second stakeholder group, to the participants in the think aloud study, and to my PhD supervisors. Thanks to Donna Lecky and the TARGET Toolkit Team in Public Health England (more recently UK Health Security Agency) for inspiring the development of this intervention.

Conflicts of Interest: The authors declare no conflict of interest. The funders had no role in the design of the study; in the collection, analyses, or interpretation of data; in the writing of the manuscript, or in the decision to publish the results. 


\section{References}

1. WHO. Global Action Plan on Antimicrobial Resistance. Available online: https://apps.who.int/iris/handle/10665/193736 (accessed on 1 November 2021).

2. HM Government. Contained and Controlled. The UK's 20-Year Vision for Antimicrobial Resistance. Available online: https://assets.publishing.service.gov.uk/government/uploads/system/uploads/attachment_data/file/773065/uk-20-yearvision-for-antimicrobial-resistance.pdf (accessed on 1 November 2021).

3. Thompson, W.; Williams, D.; Pulcini, C.; Sanderson, S.; Calfon, P.; Verma, M. The Essential Role of the Dental Team in Reducing Antibiotic Resistance; FDI World Dental Federation: Geneva, Switzerland, 2020.

4. NHS Digital. NHS Dental Statistics for England-2017-18, Annual Report. Available online: https://digital.nhs.uk/data-andinformation/publications/statistical/nhs-dental-statistics/2017-18-annual-report (accessed on 1 November 2021).

5. NHSBSA. eDEN. Available online: https://www.nhsbsa.nhs.uk/access-our-data-products/eden (accessed on 1 November 2021).

6. NICE. Managing Common Infections: Guidance for Primary Care; NICE: London, UK, 2021.

7. House of Commons. Delivering Core NHS and Care Services during the Pandemic and Beyond; Health and Social Care Committee: London, UK, 2020.

8. CQC. Dental Mythbuster 3: Dental Radiography and X-rays. Available online: https://www.cqc.org.uk/guidance-providers/ dentists / dental-mythbuster-3-dental-radiography-X-rays (accessed on 1 November 2021).

9. Thompson, W.; Douglas, G.; Pavitt, S.; Sandoe, J.; McEachan, R.; Tonkin-Crine, S. Factors associated with prescribing of systemic antibacterial drugs to adult patients in urgent primary health care, especially dentistry. J. Antimicrob. Chemother. 2019, 74, 2139-2152. [CrossRef]

10. Coxeter, P.; Del Mar, C.B.; McGregor, L.; Beller, E.M.; Hoffmann, T.C. Interventions to facilitate shared decision making to address antibiotic use for acute respiratory infections in primary care. Cochrane Database Syst. Rev. 2015, 2015, CD010907. [CrossRef]

11. Thompson, W.; McEachan, R.; Pavitt, S.; Douglas, G.; Bowman, M.; Sandoe, J. Clinician and Patient Factors Influencing Treatment Decisions: Ethnographic Study of Antibiotic Prescribing and Operative Procedures in Out-of-Hours and General Dental Practices. Antibiotics 2020, 9, 575. [CrossRef]

12. PHE. Dental Antimicrobial Stewardship Toolkit. Available online: https://www.gov.uk/guidance/dental-antimicrobialstewardship-toolkit (accessed on 1 November 2021).

13. Thompson, W. Antibiotic Prescribing: Towards a reducTion during Urgent NHS Dental Appointments in England (The APTiTUDE Study). Ph.D. Thesis, University of Leeds, Leeds, UK, 2019.

14. Jones, L.F.; Cooper, E.; Joseph, A.; Allison, R.; Gold, N.; Donald, I.; McNulty, C. Development of an information leaflet and diagnostic flow chart to improve the management of urinary tract infections in older adults: A qualitative study using the Theoretical Domains Framework. BJGP Open 2020, 4, bjgpopen20X101044. [CrossRef]

15. Human Behvaiour Change Project. Theory \& Techniques Tool. Available online: https://theoryandtechniquetool. humanbehaviourchange.org/ (accessed on 1 November 2021).

16. NICE. Shared Decision Making NICE Guideline NG197; National Institute for Health \& Care Excellence: London, UK, 2021.

17. NHSE. Commissioning Standard for Urgent Dental Care. Available online: https://www.england.nhs.uk/publication/ commissioning-standard-for-urgent-dental-care/ (accessed on 1 November 2021).

18. Michie, S.; Atkins, L.; West, R. The Behaviour Change Wheel: A Guide to Designing Interventions; Silverback Publishing: Sutton, $\mathrm{UK}, 2014$.

19. Michie, S.; Van Stralen, M.; West, R. The Behaviour Change Wheel: A new method for characterising and designing behaviour change interventions. Implement. Sci. 2011, 6, 42. [CrossRef] [PubMed]

20. Carey, R.N.; Connell, L.E.; Johnston, M.; Rothman, A.J.; De Bruin, M.; Kelly, M.P.; Michie, S. Behavior change techniques and their mechanisms of action: A synthesis of links described in published intervention literature. Ann. Behav. Med. 2019, 53, 693-707. [CrossRef] [PubMed]

21. Holmes, L.; Cresswell, K.; Williams, S.; Parsons, S.; Keane, A.; Wilson, C.; Islam, S.; Joseph, O.; Miah, J.; Robinson, E. Innovating public engagement and patient involvement through strategic collaboration and practice. Res. Involv. Engagem. 2019, 5, 1-12. [CrossRef]

22. Holmes, B.J. On the co-production of research: Why we should say what we mean, mean what we say, and learn as we go. Impact Soc. Sci. Blog 2017. Available online: https://blogs.lse.ac.uk/impactofsocialsciences/2017/09/21/on-the-co-production-ofresearch-why-we-should-say-what-we-mean-mean-what-we-say-and-learn-as-we-go/ (accessed on 1 November 2021).

23. Buckley, B.; Thijssen, D.; Murphy, R.; Graves, L.; Whyte, G.; Gillison, F.; Crone, D.; Wilson, P.; Watson, P. Making a move in exercise referral: Co-development of a physical activity referral scheme. J. Public Health 2018, 40, e586-e593. [CrossRef]

24. Holmes, B.J.; Best, A.; Davies, H.; Hunter, D.; Kelly, M.P.; Marshall, M.; Rycroft-Malone, J. Mobilising knowledge in complex health systems: A call to action. Evid. Policy 2017, 13, 539-560. [CrossRef]

25. Boivin, A.; Lehoux, P.; Burgers, J.; Grol, R. What are the key ingredients for effective public involvement in health care improvement and policy decisions? A randomized trial process evaluation. Milbank Q. 2014, 92, 319-350. [CrossRef]

26. Anthierens, S.; Tonkin-Crine, S.; Douglas, E.; Fernandez-Vandellos, P.; Krawczyk, J.; Llor, C.; Cals, J.W.; Francis, N.A.; Yardley, L.; Coenen, S. General practitioners' views on the acceptability and applicability of a web-based intervention to reduce antibiotic prescribing for acute cough in multiple European countries: A qualitative study prior to a randomised trial. BMC Fam. Pract. 2012, 13, 101. [CrossRef] [PubMed] 
27. Pouwels, K.B.; Dolk, F.C.K.; Smith, D.R.; Robotham, J.V.; Smieszek, T. Actual versus 'ideal'antibiotic prescribing for common conditions in English primary care. J. Antimicrob. Chemother. 2018, 73, 19-26. [CrossRef] [PubMed]

28. Cope, A.L.; Francis, N.A.; Wood, F.; Chestnutt, I.G. Antibiotic prescribing in UK general dental practice: A cross-sectional study. Community Dent. Oral Epidemiol. 2016, 44, 145-153. [CrossRef]

29. Cabana, M.D.; Rand, C.S.; Powe, N.R.; Wu, A.W.; Wilson, M.H.; Abboud, P.-A.C.; Rubin, H.R. Why don't physicians follow clinical practice guidelines? A framework for improvement. J. Am. Med. Assoc. 1999, 282, 1458-1465. [CrossRef]

30. Santarossa, M.; Kilber, E.N.; Wenzler, E.; Albarillo, F.S.; Sterk, E.J. Bundled up: A narrative review of antimicrobial stewardship initiatives and bundles in the emergency department. Pharmacy 2019, 7, 145. [CrossRef]

31. Jones, L.F.; Hawking, M.K.; Owens, R.; Lecky, D.; Francis, N.A.; Butler, C.; Gal, M.; McNulty, C.A. An evaluation of the TARGET (Treat Antibiotics Responsibly; Guidance, Education, Tools) Antibiotics Toolkit to improve antimicrobial stewardship in primary care-is it fit for purpose? Fam. Pract. 2018, 35, 461-467. [CrossRef] [PubMed]

32. Loffler, C.; Bohmer, F.; Hornung, A.; Lang, H.; Burmeister, U.; Podbielski, A.; Wollny, A.; Kundt, G.; Altiner, A. Dental care resistance prevention and antibiotic prescribing modification-the cluster-randomised controlled DREAM trial. Implement. Sci. 2014, 9, 27. [CrossRef]

33. Emmott, R.; Barber, S.K.; Thompson, W. Antibiotics and toothache: A social media review. Int. J. Pharm. Pract. 2021, 29, 210-217. [CrossRef]

34. Kirton, J.; Thompson, W.; Pearce, M.; Brown, J. Ability of the wider dental team to triage patients with acute conditions: A qualitative study. Br. Dent. J. 2020, 228, 103-107. [CrossRef]

35. Smith, C.M.; Shallcross, L.J.; Dutey-Magni, P.; Conolly, A.; Fuller, C.; Hill, S.; Jhass, A.; Marcheselli, F.; Michie, S.; Mindell, J.S. Incidence, healthcare-seeking behaviours, antibiotic use and natural history of common infection syndromes in England: Results from the Bug Watch community cohort study. BMC Infect. Dis. 2021, 21, 1-11. [CrossRef] [PubMed]

36. Stivers, T. Managing Patient Pressure to Prescribe Antibiotics in the Clinic. Pediatric Drugs 2021, 23, 437-443. [CrossRef]

37. Kohut, M.R.; Keller, S.C.; Linder, J.A.; Tamma, P.D.; Cosgrove, S.E.; Speck, K.; Ahn, R.; Dullabh, P.; Miller, M.A.; Szymczak, J.E. The inconvincible patient: How clinicians perceive demand for antibiotics in the outpatient setting. Fam. Pract. 2020, 37, 276-282. [CrossRef]

38. Hayes, C.V.; Mahon, B.; Sides, E.; Allison, R.; Lecky, D.M.; McNulty, C.A.M. Empowering Patients to Self-Manage Common Infections: Qualitative Study Informing the Development of an Evidence-Based Patient Information Leaflet. Antibiotics 2021, 10, 1113. [CrossRef]

39. James Lind Alliance. Oral and Dental Health. Available online: https://www.jla.nihr.ac.uk/priority-setting-partnerships/oraland-dental-health/ (accessed on 1 November 2021).

40. Dailey, Y.-M.; Humphris, G.; Lennon, M. Reducing patients' state anxiety in general dental practice: A randomized controlled trial. J. Dent. Res. 2002, 81, 319-322. [CrossRef] [PubMed]

41. Agnihotry, A.; Thompson, W.; Fedorowicz, Z.; van Zuuren, E.J.; Sprakel, J. Antibiotic use for irreversible pulpitis. Cochrane Database Syst. Rev. 2019, 5, CD004969. [CrossRef] [PubMed]

42. Cope, A.; Francis, N.; Wood, F.; Chestnutt, I. Systemic antibiotics for symptomatic apical periodontitis and acute apical abscess in adults. Cochrane Database Syst. Rev. 2018, 9, CD010136. [CrossRef]

43. Shah, S.W.V.; Thompson, W. How did COVID-19 impact on dental antibiotic prescribing across England? Br. Dent. J. 2020, 229, 601-604. [CrossRef]

44. Rabie, H.; Figueiredo, R. Provision of dental care by public health dental clinicsduring the COVID-19 Pandemic in Alberta Canada. Prim. Dent. J. 2021, 10, 47-54. [CrossRef]

45. Mian, M.; Teoh, L.; Hopcraft, M. Trends in Dental Medication Prescribing in Australia during the COVID-19 Pandemic. JDR Clin. Transl. Res. 2021, 6, 145-152. [CrossRef]

46. Kerr, I.; Reed, D.; Brennan, A.-M.; Eaton, K.A. An investigation into possible factors that may impact on the potential for inappropriate prescriptions of antibiotics: A survey of general dental practitioners' approach to treating adults with acute dental pain. Br. Dent. J. 2021, 1-6. [CrossRef]

47. Agency, U.H.S. English Surveillance Programme for Antimicrobial Utilisation and Resistance (ESPAUR) Report 2021. 2021, in production.

48. $\quad$ van der Zande, M.M.; Dembinsky, M.; Aresi, G.; van Staa, T.P. General practitioners' accounts of negotiating antibiotic prescribing decisions with patients: A qualitative study on what influences antibiotic prescribing in low, medium and high prescribing practices. BMC Fam. Pract. 2019, 20, 1-11. [CrossRef] [PubMed]

49. Asimakopoulou, K.; Newton, J.T. The contributions of behaviour change science towards dental public health practice: A new paradigm. Community Dent. Oral Epidemiol. 2015, 43, 2-8. [CrossRef] [PubMed]

50. Atkins, L.; Francis, J.; Islam, R.; O'Connor, D.; Patey, A.; Ivers, N.; Foy, R.; Duncan, E.M.; Colquhoun, H.; Grimshaw, J.M. A guide to using the Theoretical Domains Framework of behaviour change to investigate implementation problems. Implement. Sci. 2017, 12, 77. [CrossRef]

51. Lecky, D.M.; Howdle, J.; Butler, C.C.; McNulty, C.A. Optimising management of UTIs in primary care: A qualitative study of patient and GP perspectives to inform the development of an evidence-based, shared decision-making resource. Br. J. Gen. Pract. 2020, 70, e330-e338. [CrossRef] [PubMed] 